\title{
A COMPARATIVE STUDY OF 0.5\% BUPIVACAINE AND 0.75\% ROPIVACAINE IN SUPRACLAVICULAR BRACHIAL PLEXUS BLOCK BY PERIVASCULAR APPROACH: PROSPECTIVE RANDOMIZED STUDY
}

\author{
Sreeharsha Sirigeri ${ }^{1}$, Vinuta V. Patil ${ }^{2}$ \\ ${ }^{1}$ Assistant Professor, Department of Anaesthesia, DM-Wims, Wayanad. \\ ${ }^{2}$ Assistant Professor, Department of Anaesthesia, DM-Wims, Wayanad.
}

\section{ABSTRACT}

\section{OBJECTIVES}

To compare the effect of $30 \mathrm{ml}$ of $0.5 \%$ bupivacaine and $30 \mathrm{ml}$ of $0.75 \%$ ropivacaine in supraclavicular brachial plexus block with respect to onset time of sensory blockade, onset time of motor blockade, duration of sensory blockade, duration of motor blockade, duration of analgesia and any side effects.

\section{MATERIALS AND METHODS}

Sixty patients of ASA-I and II undergoing elective upper limb surgeries lasting more than 30 minutes were randomly divided into Group B and Group R, which received $30 \mathrm{ml}$ of $0.5 \%$ bupivacaine and $0.75 \%$ ropivacaine respectively. Sensory and motor block onset and duration and duration of analgesia were evaluated statistically using unpaired t-test and p-value $<0.05$ was considered significant.

\section{RESULTS}

The onset time of sensory block was faster in Group R compared to Group B having a mean value of $16.13 \pm 3.05$ minutes and $17.70 \pm 2.35$ minutes respectively. The onset time of motor block was faster in Group R compared to Group B having a mean value of $23.90 \pm 1.83$ minutes and 25.43 \pm 2.22 minutes respectively. The duration of sensory and motor block (Mean-minutes) was 480.3 and 472.8 in group R and 472.1 and 460.2 in group B. The duration of post-operative analgesia was 504.2 minutes in Group R and 499.6 minutes in Group B.

\section{CONCLUSION}

Group R provided statistically significant rapid onset of sensory and motor blockade, prolonged duration of both sensory and motor blockade, prolonged duration of analgesia than Group B for upper limb surgeries. There were no significant differences in haemodynamic changes and complications.

\section{KEYWORDS}

0.5\% Bupivacaine, 0.75\% Ropivacaine, Supraclavicular Plexus Block.

HOW TO CITE THIS ARTICLE: Sirigeri S, Patil VV. A comparative study of $0.5 \%$ bupivacaine and $0.75 \%$ ropivacaine in supraclavicular brachial plexus block by perivascular approach: Prospective randomized study. J. Evolution Med. Dent. Sci.. 2016;5(13):568-571,DOI: 10.14260/jemds/2016/130

\section{INTRODUCTION}

Regional anaesthesia in the form of block at the supraclavicular approach to the Brachial plexus is often used for upper limb surgeries. It provides anaesthesia by blocking the middle and lower plexus (Median, Radial and Ulnar N). The use of supraclavicular block as the primary anesthetic technique avoids the complications associated with general anaesthesia, airway instrumentation, provides better postoperative analgesia. Bupivacaine is a long-acting local anaesthetic. Due to its long duration of action and combined with its high quality sensory blockade compared to motor blockade it has been the most commonly used local anaesthetic for peripheral nerve blocks. Ropivacaine is a newer, long-acting local anaesthetic whose neuronal blocking potential used in peripheral nerve blockade seems to be equal or superior to Bupivacaine. ${ }^{1}$ Ropivacaine is less lipophilic than

Financial or Other, Competing Interest: None.

Submission 30-12-2015, Peer Review 25-01-2016,

Acceptance 30-01-2016, Published 13-02-2016.

Corresponding Author:

Dr. Sreeharsha Sirigeri,

No.313, Residential Block 1

DM-Wims, Naseera Nagar, Meppadi-673577,

Wayanad Dist., Kerala.

E-mail: sree272727@gmail.com

DOI:10.14260/jemds/2016/130 bupivacaine and that together with its stereo selective properties. ${ }^{2}$ contributes to ropivacaine having a significantly higher threshold for cardiotoxicity and CNS toxicity than bupivacaine in healthy volunteers. ${ }^{3-5}$

Studies shows that it has significantly greater safety margin over Bupivacaine because of lower CNS and cardiac toxicity. ${ }^{6}$ and hence can be used in higher concentrations also. One of the drawbacks of Ropivacaine mentioned is its less intense motor blockade at similar concentration compared to Bupivacaine. ${ }^{7}$ ropivacaine has similar potency to bupivacaine at higher doses (Eg: Doses required for peripheral nerve blocks for surgical anaesthesia), Ropivacaine is less potent than bupivacaine and levobupivacaine at lower doses, such as those used for epidural or intrathecal analgesia.

Hence, here is an attempt through the study to compare effect of Bupivacaine with Ropivacaine in supraclavicular brachial plexus block.

This study is designed to compare $30 \mathrm{~mL}$ of Bupivacaine $0.5 \%$ and $30 \mathrm{~mL}$ of Ropivacaine $0.75 \%$ for supraclavicular brachial plexus block by perivascular approach.

\section{MATERIALS AND METHODS}

Our study is a randomised prospective clinical study of patients undergoing elective lower limb orthopaedic surgeries receiving either epidural ropivacaine or bupivacaine after 
obtaining written informed consent and institutional ethical committee approval. Sixty patients aged between 18 years and 60 years of physical status ASA grade 1 and ASA grade 2 weight of $60 \mathrm{~kg}$ to $80 \mathrm{~kg}$ were included in the study. Exclusion criteria included known patient refusal, allergy to local anaesthetics, local infections, bleeding disorders, coagulopathy, mental illness and patients on anti-arrhythmic treatment. Each patient was visited pre-operatively and the procedure explained and written and informed consent was obtained. Complete blood count, blood grouping, blood sugars, bleeding time, clotting time, blood urea, serum creatinine, serum electrolytes (Sodium, potassium, chloride), chest x-ray, and ECG were done. Patients were randomly allocated by simple randomisation into two groups of 30 each ( $85 \%$ power) and $\alpha$ error of $0.05 \%$ to

Group B - i.e. Bupivacaine group receiving 30mL Bupivacaine $0.5 \%(5 \mathrm{mg} / \mathrm{mL})$.

Group R - i.e. Ropivacaine group receiving $30 \mathrm{~mL}$ Ropivacaine $0.5 \%(5 \mathrm{mg} / \mathrm{mL})$.

All the patients were pre-medicated with tablet alprazolam $0.5 \mathrm{mg}$ overnight and the morning of surgery. All the necessary equipments and drugs needed for administration of general anaesthesia were kept ready in order to manage failure of block. Intravenous access obtained in the limb opposite to that undergoing surgery with a large bore IV cannula. After connecting the routine pre-induction monitors, baseline values of blood pressure, heart rate, oxygen saturation were recorded. Patient was placed in supine position with the head turned away from the side to be blocked. Arm to be anaesthetized adducted and extended towards the ipsilateral knee as far as possible. Supraclavicular area aseptically prepared and draped. An intradermal wheal raised about $1 \mathrm{~cm}$ above the mid-clavicular point. Subclavian artery palpable in supraclavicular fossa used as landmark. A 23-gauge needle inserted behind the artery in backwardinward-downward direction till paresthesia in the forearm elicited. After negative aspiration for blood, $30 \mathrm{~mL}$ of respective drug was injected depending on whether patient is allotted to either of group B or R.

The effect on the following parameters were observed: Onset time of Sensory blockade, onset time of Motor blockade, Duration of Sensory blockade, Duration of Motor blockade, Duration of Analgesia and any side effects. Sensory block was assessed by pin prick with $23 \mathrm{~g}$ hypodermic needle in skin dermatomes c4-t2 once in every minute for initial 30 minutes and then after every 30 minutes till patient regained normal sensations and graded according to Visual Analogue Scale (VAS). Quality of motor block was assessed at the same intervals and graded according to Modified Lovett's Scoring journal as Grade 6-Normal, Grade 5-slightly reduced muscular force, Grade 4-pronounced reduction, Grade 3-slightly impaired mobility, Grade 2-pronounced mobility impairment, Grade 1-Almost complete paralysis, Grade 0-Complete paralysis.

Onset time of Sensory blockade-taken from the completion of injection of study drug till the patient does not feel the pin prick. (Visual analogue scale score-0). Onset time of Motor blockade-taken from the completion of injection of study drug till the patient develops motor blockade. (Lovett's Grade 1). Duration of Sensory blockade - taken from the onset of Sensory blockade till the patient feels pin prick. (Visual analogue scale of 2). Duration of Motor blockade-taken from the Onset of Motor blockade till complete recovery of motor power. (Lovett's grade 6). Duration of Analgesia-taken as the time between the onset of sensory action and onset of pain, was the time when patient received first dose of analgesic. Supplemental analgesia was given when visual analogue scale score was more than 4 .

Patients were observed for bradycardia, convulsions, restlessness, disorientation, drowsiness, nausea, vomiting and any other complications.

\section{STATISTICAL ANALYSIS}

Data collected were coded, tabulated and then analyzed using SPSS ${ }^{\circledR} 20$ computer package. All the values were expressed as Mean \pm Standard deviation, statistical comparison was performed by student's t-test.

A two tailed $p$ value of $>0.05$ was considered to be statistically not significant, a p value of $<0.05$ as statistically significant, a $\mathrm{p}$ value of $<0.01$ as statistically highly significant and a $p$ value of $<0.001$ as statistically very highly significant.

\section{RESULTS}

A total of 60 patients consented to participate in the study that were randomly allocated into groups with 30 in each group. Group B received $30 \mathrm{~mL}$ of $0.5 \%$ Bupivacaine. Group R received $30 \mathrm{~mL}$ of $0.75 \%$ Ropivacaine for Brachial plexus block by supraclavicular approach.

Demographic profiles were almost similar in both the groups.

\begin{tabular}{|c|c|}
\hline 0 & No pain \\
\hline 2 & Annoying (Mild pain) \\
\hline 4 & Uncomfortable (Moderate pain) \\
\hline 6 & Dreadful (Severe pain) \\
\hline 8 & Horrible (Vey severe pain) \\
\hline 10 & Agonizing (Worst possible pain) \\
\hline \multicolumn{2}{|c|}{ Table 1: Sensory block grading for pin prick } \\
\hline
\end{tabular}

\begin{tabular}{|l|c|}
\hline Grade 6 & Normal \\
\hline Grade 5 & Slightly reduced muscular force \\
\hline Grade 4 & Pronounced reduction \\
\hline Grade 3 & Slightly impaired mobility \\
\hline Grade 2 & Pronounced mobility impairment \\
\hline Grade 1 & Almost complete paralysis \\
\hline Grade 0 & Complete paralysis \\
\hline \multicolumn{2}{|c|}{ Table 2: Motor block graded according to Modified } \\
Lovett's Scoring as
\end{tabular}

\begin{tabular}{|c|c|c|c|}
\hline Study Variables & Group B & Group R & P value \\
\hline $\begin{array}{c}\text { Sensory onset } \\
\text { time }\end{array}$ & $17.70 \pm 2.35$ & $16.13 \pm 3.05$ & $<0.001$ \\
\hline Motor onset time & $25.43 \pm 2.22$ & $23.90 \pm 1.88$ & $<0.001$ \\
\hline \multicolumn{3}{|c|}{$\begin{array}{c}\text { Table 3: Comparison of Group B and Group R on The } \\
\text { Basis of Onset Time of Sensory and Motor Blockade }\end{array}$} \\
\hline
\end{tabular}

In Group B, the mean onset time of Sensory blockade and Motor blockade was $17.70 \pm 2.35 \mathrm{~min}$ and $25.43 \pm 2.22 \mathrm{~min}$ respectively when compared to Group $\mathrm{R}$ having Onset time of sensory blockade and Motor blockade of $16.13 \pm 3.05 \mathrm{~min}$ and $23.90 \pm 1.88$ min respectively.

\section{Comparison of Mean Onset Time between the groups}

Onset time of Sensory and Motor blockade was earlier in Group R when compared with Group B. The p value was $<0.001$, which is statistically very highly significant. 


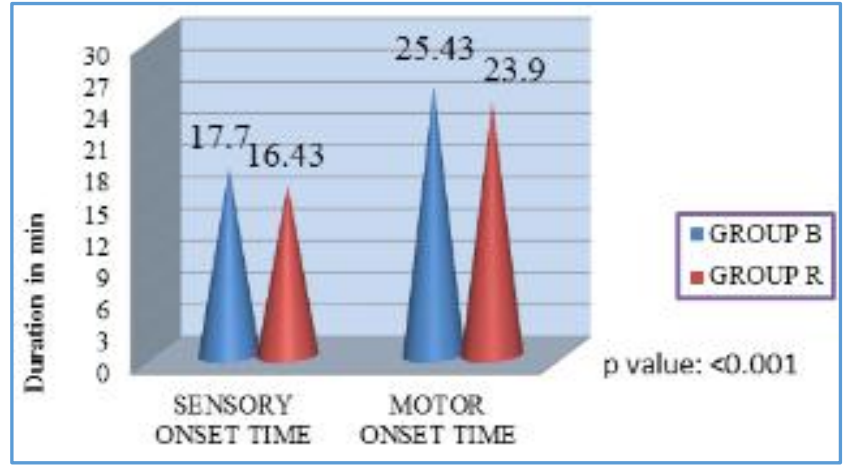

Fig. 1: Comparison of Onset Time of Sensory and Motor Blockade in Two Groups

\begin{tabular}{|c|c|c|c|}
\hline $\begin{array}{c}\text { Study } \\
\text { Variables }\end{array}$ & Group B & Group R & P value \\
\hline $\begin{array}{c}\text { Duration of } \\
\text { sensory } \\
\text { blockade }\end{array}$ & $342.00 \pm 47.66$ & $392.00 \pm 42.38$ & 0.001 \\
\hline $\begin{array}{c}\text { Duration of } \\
\text { motor blockade }\end{array}$ & $369.00 \pm 41.05$ & $436.00 \pm 37.29$ & 0.002 \\
\hline $\begin{array}{c}\text { Table 4: Comparison of Group B and Group R on the Basis } \\
\text { of Duration of Sensory and Motor Blockade }\end{array}$ \\
\hline
\end{tabular}

In Group B, the Mean Duration of Sensory blockade and Motor blockade was $342.00 \pm 47.66 \mathrm{~min}$ and $369.00 \pm 41.05 \mathrm{~min}$ respectively when compared to Group $\mathrm{R}$ having Mean Duration of sensory blockade and Motor blockade of $392.00 \pm 42.38 \mathrm{~min}$ and $436.00 \pm 37.29 \mathrm{~min}$ respectively.

Comparison of Mean Duration time of sensory and motor blockade between the groups

Duration of Sensory and Motor blockade was prolonged in Group R when compared with Group B. The p value was 0.001 and 0.002 respectively, which is statistically very highly significant.

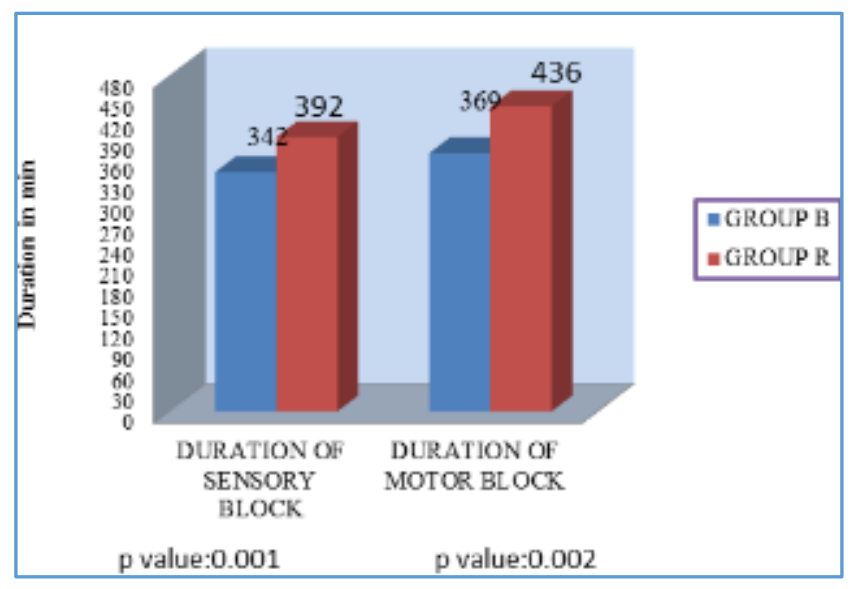

Fig. 2: Comparison of Duration of Sensory and Motor Blockade in Two Groups

\begin{tabular}{|c|c|c|c|}
\hline $\begin{array}{c}\text { Study } \\
\text { Variables }\end{array}$ & Group B & Group R & P value \\
\hline $\begin{array}{c}\text { Duration of } \\
\text { analgesia }\end{array}$ & $372.00 \pm 42.86$ & $441.00 \pm 36.52$ & 0.004 \\
\hline \multicolumn{3}{|c|}{ Table 5: Comparison of Group B and Group R on } \\
the Basis of Duration of Analgesia \\
\hline
\end{tabular}

In Group B, the Mean Duration of Analgesia was $372.00 \pm 42.86$ min when compared to Group R having Mean Duration of Analgesia of $441.00 \pm 36.52 \mathrm{~min}$.
Comparison of Mean Duration time of Analgesia between the groups

Duration of Analgesia was prolonged in Group $\mathrm{R}$ when compared with Group B. The p value was 0.004 , which is statistically very highly significant.

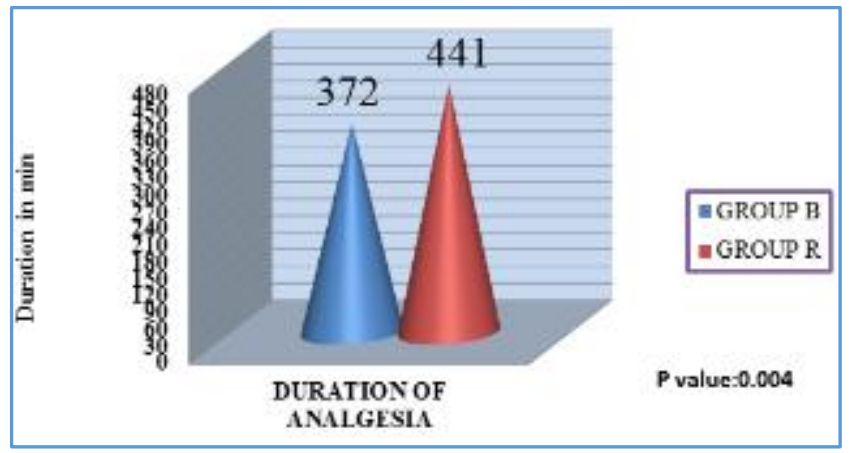

Fig. 3: Comparison of Duration of Analgesia in two groups

\section{HAEMODYNAMICS}

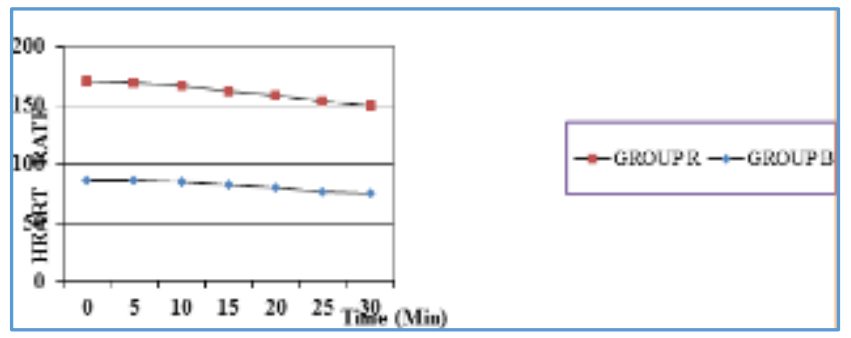

Fig. 4: Comparison of Heart Rate in two group's P value

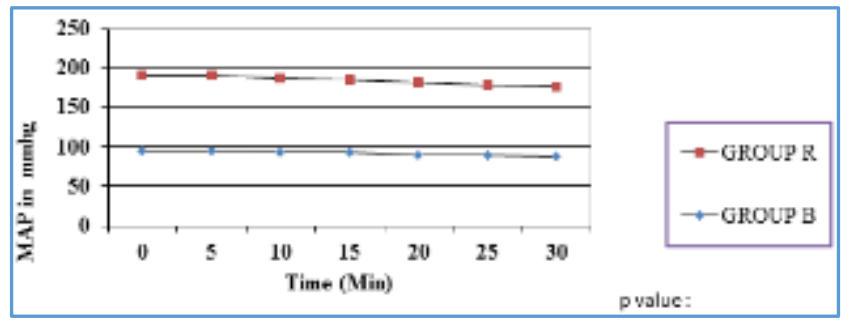

Fig. 5: Comparison of Mean Blood Pressure in two groups

\section{DISCUSSION}

Peripheral nerve blocks have become important in clinical practice because of their role in post-operative pain relief, shortening of patient recovery time and avoiding risks and adverse effects of General Anaesthesia Ropivacaine was identified in 1957.

Patient demographic profiles with respect to age, sex, height or weight were almost similar. The type and duration of surgeries performed were almost identical in both the groups (Statistically not significant). In our study, we observed that onset time of sensory block was faster in Group R compared to Group B having a mean value of $16.13 \pm 3.05$ minutes and $17.70 \pm 2.35$ minutes respectively. Similarly the onset time of Motor block was faster in Group R compared to Group B having a mean value of $23.90 \pm 1.83$ minutes and $25.43 \pm 2.22$ minutes respectively. The onset of sensory block and motor block are statistically significant. The above observations were similar to studies conducted by K Shaw et al. ${ }^{8}$ Singelyn FJ. ${ }^{1}$ and Himatvaghadia et al. ${ }^{9}$ Hence, we conclude that Ropivacaine $0.75 \%$ has an advantage of Early onset of Sensory and Motor 
blockade when compared to Bupivacaine $0.5 \%$ for Supraclavicular brachial plexus block at equal volume.

Duration of sensory block Group B and Group R were $342.00 \pm 47.66$ minutes $392.00 \pm 42.38$ minutes respectively and was statistically significant. The Duration of Motor block Group B and Group R were 369.00 \pm 41.05 minutes $436.00 \pm 37.29$ minutes respectively. Both duration of sensory and motor blockade were statistically significant. The quality and duration of motor blockade has been a matter of debate and controversy with respect to Ropivacaine, but in our study at concentration of $0.75 \%$ the duration of blockade was prolonged compared to $0.5 \%$ at equal volumes, albeit the quality appears similar. McGlade DP et al. ${ }^{10}$ showed that duration of motor block was significantly longer in the $0.75 \%$ ropivacaine group as compared to $0.5 \%$ bupivacaine. Reader JC et al. ${ }^{11}$ Found that motor blockade with $0.75 \%$ ropivacaine was comparable to $0.5 \%$ bupivacaine. However, studies conducted by McLellankj, Faulds D.12 concluded that Ropivacaine is a well-tolerated regional anaesthetic with an efficacy broadly similar to that of bupivacaine, but has a lower propensity to produce Motor blockade.

The Duration of Analgesia with Group B and Group R were $372.00 \pm 42.86$ minutes and $441.00 \pm 36.52$ minutes respectively. The time for demand of analgesics was prolonged in Group R compared to Group B and the difference was statistically significant. Our data agree with several review articles. ${ }^{10,13}$

There were no significant changes in mean pulse rate and mean arterial pressure perioperatively between two groups in present study, findings shared by other studies. ${ }^{8}$ Only 2 patients of group $\mathrm{B}$ had nausea $\mathrm{N}$ vomiting compared to none of the patients in ropivacaine group. No other significant side effects were observed in both the groups similar to other studies. ${ }^{1,9,12}$

\section{CONCLUSION}

On the basis of our study, we can draw the conclusion that at equal volumes Ropivacaine $0.75 \%$ has an advantage over Bupivacaine $0.5 \%$ for Supraclavicular Brachial Plexus block in terms of early onset of both Sensory and Motor blockade, Prolonged Duration of both Motor and Sensory blockade, Prolonged Duration of Analgesia. Both the drugs maintain stable hemodynamic profile perioperatively and are devoid of any side effects at the concentration and volumes used for the study.

\section{REFERENCES}

1. Lew D, Jerry D, Vloka et al. Ropivacaine for peripheral nerve blocks: are there advantages. Techniques of Regional Anaesthesia and Pain Management 2001; volume 5, issue 2:56-59.

2. Kindler $\mathrm{CH}, \mathrm{Paul} \mathrm{M}$, Zou H, et al. Amide local anaesthetics potently inhibit the human tandem pore domain background K+ channel TASK-2 (KCNK5). J Pharmacol Exp Ther 2003;306:84-92.

3. Graf BM, Abraham I, Eberbach N, et al. Differences in cardiotoxicity of bupivacaine and ropivacaine are the result of physiochemical and stereoselective properties. Anesthesiology 2002;96:1427-34.

4. Dony P, Dewinde V, Vanderick B, et al. The comparative toxicity of ropivacaine and bupivacaine at equipotent doses in rats. Anesth Analg 2000;91:1489-92.

5. Knudsen K, Beckman Suurküla M, Blomberg S, et al. Central nervous and cardiovascular effects of IV infusions of ropivacaine, bupivacaine and placebo in volunteers. Br J Anaesth 1997;78:507-14.

6. Singelyn FJ. Clinical application of ropivacaine for upper extremity. Current topics in medicinal chemistry, 2001; volume 1, number 3:219-225.

7. Feldman HS, Arthur GR, Covino BG. Comparative systemic toxicity of convulsant and supraconvulsant doses of intravenous ropivacaine, bupivacaine and lidocaine in the conscious dog. Anaesthesia Analgesia 1989;69:794-801.

8. Ellis H, Feldman S, et al. Anatomy for Anaesthetists. 8th ed. Massachusetts 2004;64:307-14.

9. Vaghadia H, Chan V, Ganapathy S, et al. A multicentric trial of Ropivacaine $7.5 \mathrm{mg} / \mathrm{mL}$ vs bupivacaine $5 \mathrm{mg} / \mathrm{mL}$ for supraclavicular brachial plexus anesthesia. Canadian Journal of Anesthesia, 1999;46-10: pp 946-951.

10. McGlade DP, Kalpokas MV, Mooney PH. A comparison of $0.5 \%$ Ropivacaine and $0.5 \%$ Bupivacaine for axillary brachial plexus Anaesthesia. Anaesthesia intensive care 1998;26:515-520.

11. Raeder JC, Drosdahl S, Klaastad O, et al. Axillary brachial plexus block with Ropivacaine $7.5 \mathrm{mg} / \mathrm{mL}$. A comparative study with Bupivacaine $5 \mathrm{mg} / \mathrm{mL}$. Acta Anesthesiol Scand 1999;43:794-798.

12. McClellan KJ, Faulds D. Ropivacaine, an update of its use in regional anaesthesia. Drugs 2000;60:1065-1093.

13. Hickey R, Hoffman J, Ramamurthy S, et al. A comparison of Ropivacaine $0.5 \%$ and Bupivacaine $0.5 \%$ for brachial plexus block. Anaesthesiology 1991;74:639-642. 